\title{
Pericentric inversion in human chromosome 1 and the risk for male sterility
}

\author{
ANN C CHANDLEY, S MCBEATH, R M SPEED, L YORSTON, AND \\ T B HARGREAVE* \\ From the MRC Clinical and Population Cytogenetics Unit; and ${ }^{*}$ University of Edinburgh, Department of \\ Surgery (Urology), Western General Hospital, Edinburgh EH4 $2 X U$.
}

SUMMARY A pericentric inversion in chromosome 1 of a severely oligospermic human male is reported. Pachytene analysis in microspread preparations shows an absence of full loop formation in the inversion bivalent and only the rare occurrence of a partial loop. The majority of cells exhibit extensive asynapsis across the inverted segment, or a normal looking synaptonemal complex indicative of heterologous pairing along the length of the inversion. Crossing over is reduced in the No 1 bivalent with only a rare chiasma being seen in the inverted region at metaphase I. Males heterozygous for a pericentric inversion in chromosome 1 appear to be at severe risk for infertility brought about by spermatogenic disturbance. The dearth of full loops at prophase in this patient, and in other pericentric inversion cases studied both in man and other species, raises the question of whether recombinant offspring might be rarer than anticipated on a theoretical basis owing to asynapsis or early heterologous synapsis across inverted segments.

An extensive search of human cytogenetic publications since 1970 has revealed 20 published cases of pericentric inversion in chromosome 1 , of which nine have been found in adult males. Of these, eight have been ascertained through male sterility with associated oligo- or azoospermia (table 1).

Ascertainment of pericentric inversions in man in general is not made through male sterility but by the birth of a child with congenital malformations or spontaneous abortion resulting from a duplicationdeficiency product from the carrier parent. Pericentric inversion in chromosome 1 thus appears to carry a special risk for male infertility through spermatogenic impairment, and this holds true regardless of breakpoint positioning.

A further case of pericentric inversion in chromosome 1 is now reported in an oligospermic man. Meiotic analyses at prophase and metaphase I show severe disruption of pairing in the inversion bivalent together with associated synaptic disturbance in other members of the complement. The report corroborates and extends previous meiotic analyses made on human male inversion 1 heterozygotes. ${ }^{4} 57$

\section{Case report}

Patient WSM 213, aged 31 years, was referred to the male infertility clinic of the Western General Hospital, Edinburgh, in November 1985. He and his wife had been trying for a child for the last 18 months of a five year marriage. He was phenotypically normal. No abnormality which might account for the failure to conceive could be traced to his wife. Tests indicated spontaneous regular ovulation and normal tubal patency and anatomy.

\section{PHYSICAL EXAMINATION}

The patient's height was $177 \mathrm{~cm}$ and weight $73.5 \mathrm{~kg}$. The testes were small (mean volume $14 \mathrm{cc}$, normal range for Caucasians 15 to $45 \mathrm{cc}$ ), but the penis and scrotum were normal. A small varicocele was present on the left side.

SEMINAL ANALYSIS

Two semen samples, analysed in the autumn of 1985, showed severe oligospermia. The best sample gave a count of $1 \times 10^{6}$ per ml and a motility of $80 \%$ normal.

HORMONE INVESTIGATIONS

Raised levels of $\mathrm{LH}$ and FSH were recorded: $\mathrm{LH}$ 


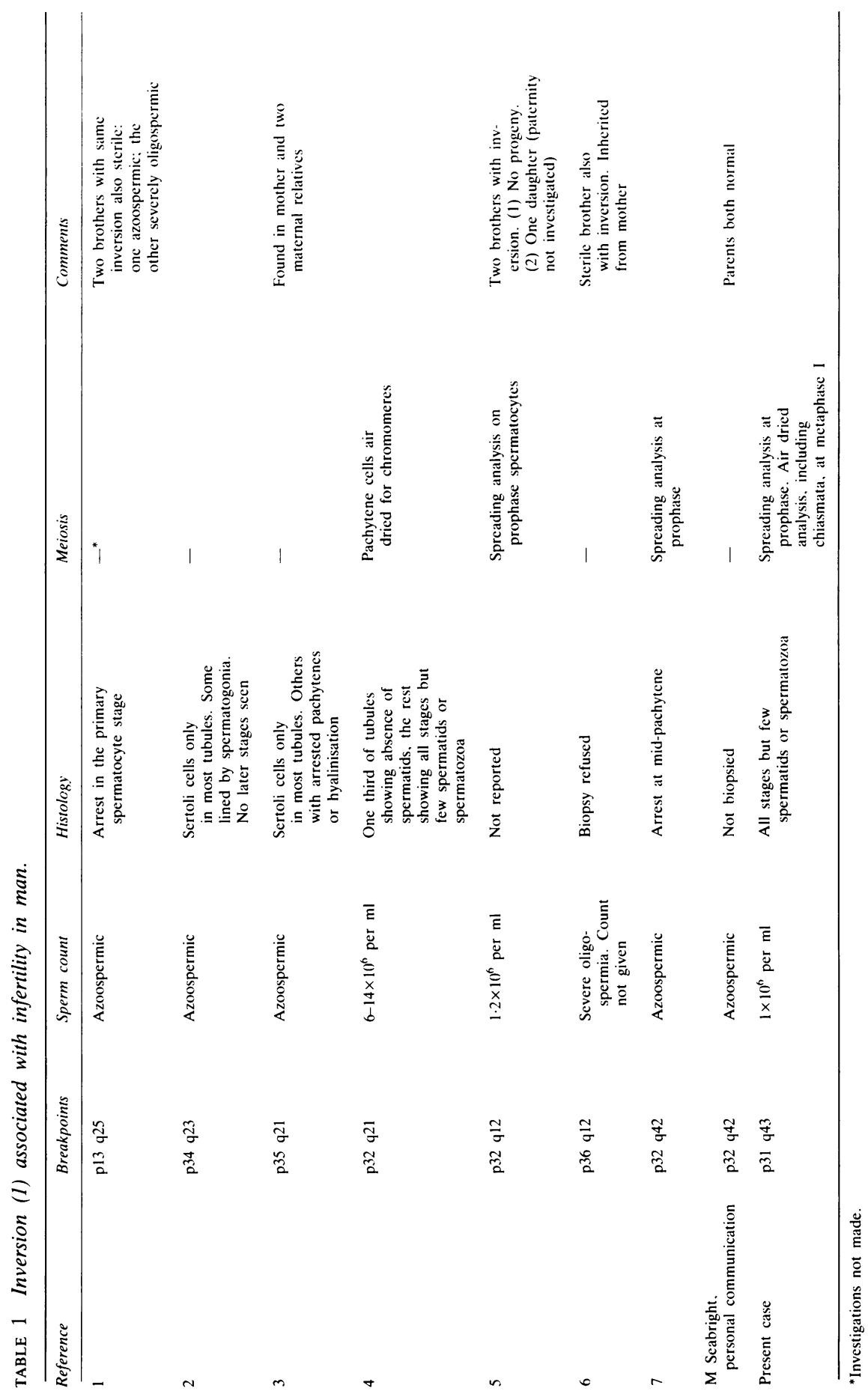

$\overrightarrow{\mathrm{F}}$

듬

$\frac{\bar{\sigma}}{\frac{1}{2}}$

ㅁำ

क

$\vec{\circ}$

$\overrightarrow{\vec{\omega}}$

产

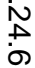

ज్

옥

ट्

응

ฏ

응

혹

릉

긍

훅

을

윽

금

N

กิ

무

음

$\stackrel{0}{9}$

뭉

옹

뭉

ㅁ

윰 
$11.8 \mathrm{U} / 1$ (normal range 1 to $6.5 \mathrm{U} / \mathrm{l}$ ), FSH $6.4 \mathrm{U} / \mathrm{l}$ (normal range 1 to $6 \mathrm{U} / \mathrm{l})$. Testosterone $(27 \cdot 2 \mathrm{ng} / \mathrm{ml}$ ) was within the normal range (10 to $30 \mathrm{ng} / \mathrm{ml}$ ).

\section{TESTICULAR HISTOLOGY}

A testicular biopsy was taken from the right side in April 1986. The seminiferous tubules were of normal diameter and no thickening of the tunica propria was seen. Spermatogenic activity was present in all tubules, but there was a deficiency of spermatids and a severe paucity of spermatozoa in the lumina. Leydig cells were well represented and there were no inflammatory or vascular abnormalities.

\section{CYTOGENETIC METHODS}

Conventional techniques were used to perform a somatic chromosome analysis on blood lymphocytes of WSM 213, cells being prepared by G and C banding techniques. ${ }^{89}$ Analysis at meiotic metaphase I (MI) was carried out on air dried cells, ${ }^{10}$ stained with carbol fuchsin, ${ }^{11}$ or by $\mathrm{C}$ banding. ${ }^{12}$ Microspread preparations of prophase spermatocytes were made according to methods previously described $^{13}$ and examined at electron microscope (EM) level.

\section{Results}

BLOOD LYMPHOCYTE ANALYSIS

A total of $10 \mathrm{G}$ banded cells showed WSM 213 to have a large pericentric inversion in chromosome 1 , with breakpoints at p31 and q43 (fig 1a). $\mathrm{C}$ banding showed the changed position of the large centromeric block of heterochromatin in the abnormal chromosome (fig $1 \mathrm{~b}$ ). A repeat blood sample taken at the time of the testicular biopsy confirmed the above findings. The inversion is

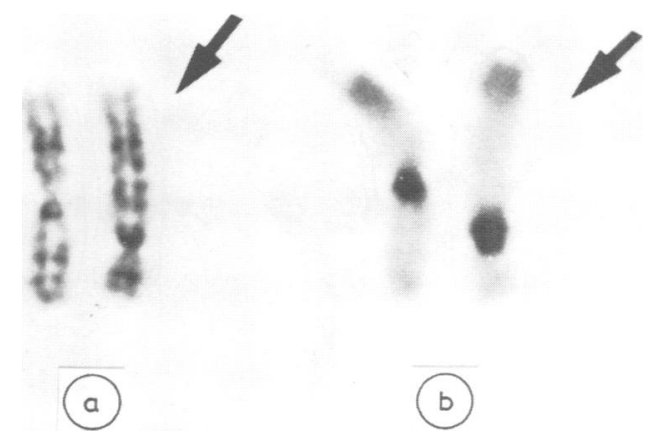

FIG 1 Chromosome pair No I. (a) G banded. (b) C banded. shown diagrammatically in fig 2 . The karyotype is $46, X Y$,inv(1)(p31q43).

AIR DRIED MEIOTIC ANAIYSIS

Analysis of 329 dividing cells in the carbol fuchsin stained testicular suspension gave a distribution count of: spermatogonial mitosis $(16 \%)$, MI $(78 \%)$, MII $(6 \%)$. This indicated an arrest in development for many spermatocytes between the first and second meiotic divisions. Severe degenerative changes affected a high proportion of MI cells, but a total of 65 healthy cells in this stage was found in a scan of six slides. More than half $(39 / 65$ or $60 \%)$ showed failure of $\mathrm{X}$ and $\mathrm{Y}$ attachment, one of these cells also showing a pair of small autosomal univalents. A further cell, with attached sex chromosomes, showed three small pairs of autosomal univalents. This indicates a high degree of synaptic disturbance in the non-inverted portion of the genome. Autosomal univalents are usually extremely rare in human male meiotic material, ${ }^{14}{ }^{15}$ while $X$ and $\mathrm{Y}$ univalents are found with a mean frequency of about $20 \%$ in our material. ${ }^{15}$ Chiasma counts for 20 cells gave a mean of $55 \cdot 2$ (range 47 to 63 ) per cell, a figure within the normal range.

Although it was not always possible to identify unambiguously the inversion bivalent in the carbol fuchsin preparations, about two-thirds of the $65 \mathrm{MI}$

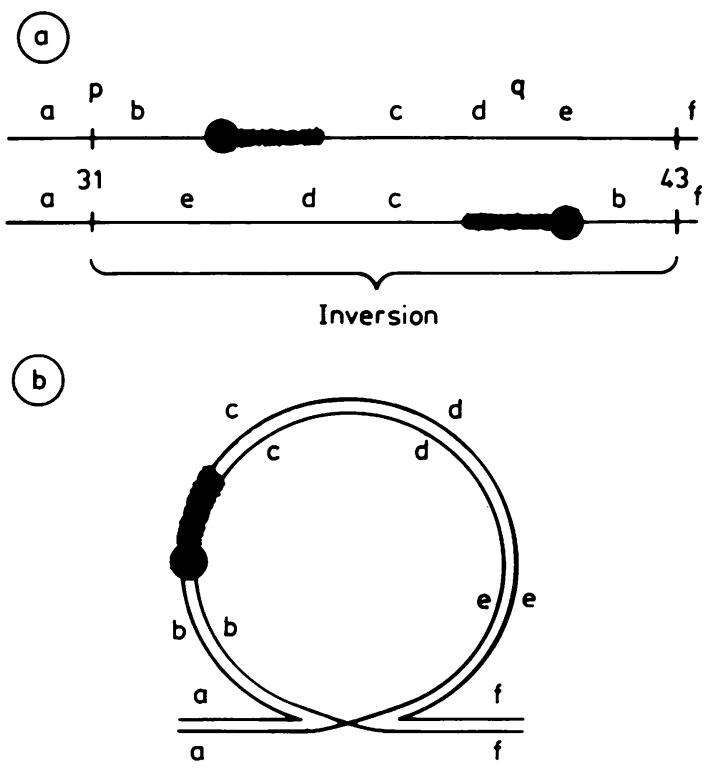

FIG 2 (a) Diagrammatic representation of the inversion in chromosome 1. (b) The theoretical loop predicted for bivalent No I at meiotic prophase. 
divisions scanned did show a large bivalent which lacked chiasmata over an extensive interstitial segment (fig 3a). This was interpreted as the No 1 bivalent. A single cell showed total failure of chiasma formation over a large segment which resulted in a bivalent held together by chiasmata at only one end, the arms freely diverging at the other (fig 3b). Pale gaps in this bivalent indicated the pericentromeric regions, these being seen to lie in asymmetrical positions across the bivalent, as expected for an inversion. Unequivocal evidence of asymmetrical positioning of the centromeres in the inversion bivalent was obtained, however, from the $\mathrm{C}$ banded preparations (fig 3c). A total of $19 \mathrm{MI}$ divisions was analysed over four thoroughly scanned $\mathrm{C}$ banded slides. Chiasma counts for the inversion bivalent showed them to have two chiasmata $(n=8) \stackrel{\mathbb{Q}}{;}$ three chiasmata $(n=9)$, or four chiasmata $(n=2) \overrightarrow{\vec{F}}$ The mean chiasmata frequency for the inversion bivalent was 2.68 compared with a normal mean of 3.90 for the normal No 1 bivalent. ${ }^{14}$ Only in one cele (fig 3d) was evidence found of chiasma formation within the inverted segment of bivalent No 1 .

MEIOTIC PROPHASE ANALYSIS BY

MICROSPREA DIN G

A total of 122 spread prophase cells was found on $2 \vec{z}$ grids examined at EM level. A high proportion? $(55 / 122$ or $45 \%)$ showed changes in the synapto nemal complexes (SC) indicative of degenerationi principle features being fragmentation of the axes of pairing disturbance or both over a major part of thew

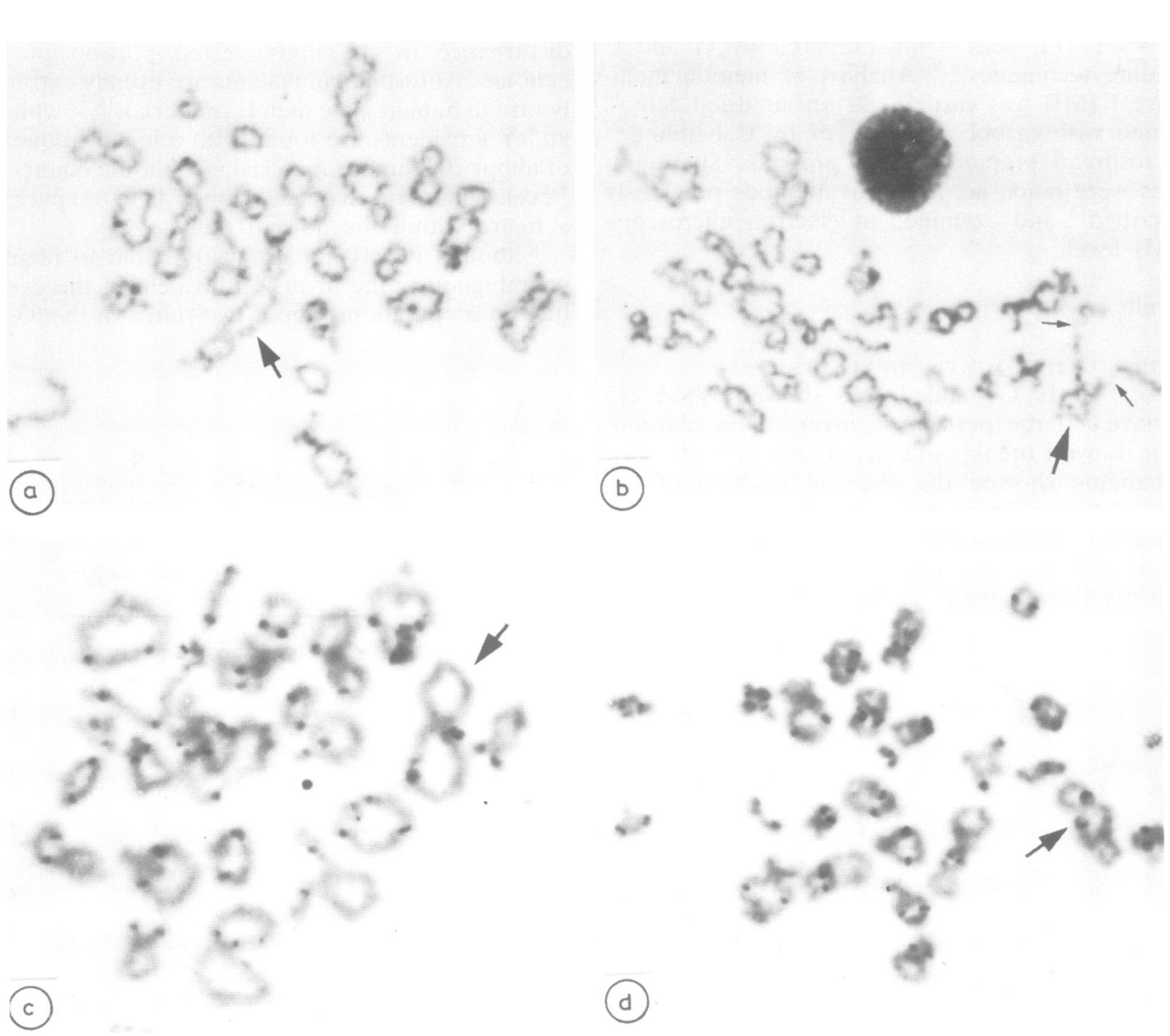

FIG 3 Air dried MI preparations from the inversion 1 heterozygote. $(a, b)$ Carbol fuchsin stain. (c, $d) C$ banding. Large arrows indicate the inversion bivalent. Small arrows in (b) show pale staining gaps which indicate asymmetricalo
centromere positions. 
complement (fig 4). For the remaining 67 healthy looking prophases, the results of the SC analysis are given in table 2. Each cell was classified according to XY pairing stage, by the scheme of Solari, ${ }^{16}$ which recognises six prophase stages (types $\mathrm{O}-\mathrm{V}$ ). It was obvious that few cells with paired sex chromosome axes had progressed beyond early pachytene, only three cells being classified as types III and IV (late pachytene) and none being classed as type $\mathrm{V}$ (diplotene). In normal meiotic preparations approximately $65 \%$ of all prophase spermatocytes are usually found among the types III to $\mathrm{V}$ categories. ${ }^{13}$ For 21 cells showing separated $X$ and $Y$ axes $(31.3 \%$ of the total analysed), thickening and condensation

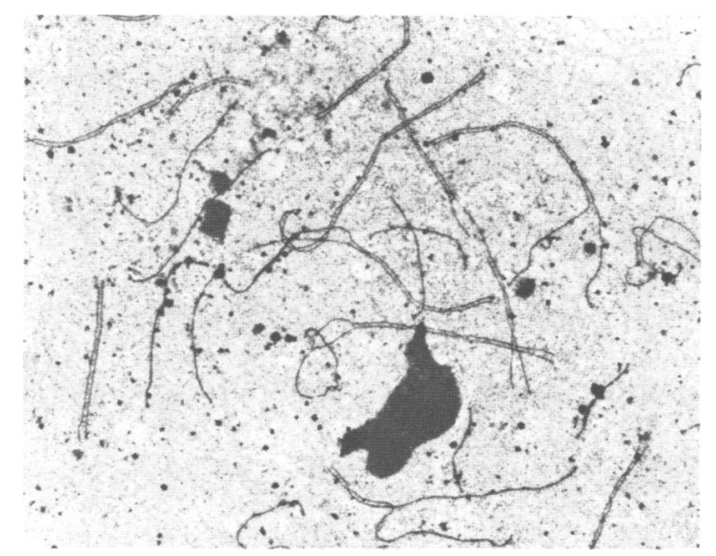

FIG 4 Detail from a prophase spread viewed at EM level. Pairing disturbance is indicated by the numerous single axes present in the cell. of the sex chromosome axes was a characteristic feature, as previously noted. ${ }^{13}$ The recorded incidence of separated $\mathrm{X}$ and $\mathrm{Y}$ axes in normal prophase material prepared by spreading in our laboratory is $0.9 \% .{ }^{13}$ Asynapsis affecting both the autosomes and sex pair at prophase of meiosis was thus a marked feature of the inversion heterozygote.

For the majority of prophase cells, no problem was encountered in recognising one long anomalous $\mathrm{SC}$ which was interpreted as corresponding to the inversion bivalent. In general, this showed a region of moderate to extensive interstitial asynapsis which was complete (fig 5a) or with a twist in the axes (fig $5 b$ ), suggestive in some cells of an attempt to initiate synapsis at one point (fig 5c). The twists, however, were seen somewhat randomly positioned along the unpaired segment, sometimes being closer to the longer paired distal SC (interpreted as homologously paired distal $1 \mathrm{p}$ ) (for example, fig $5 \mathrm{~b}$ ), and at other times being closer to the shorter paired distal segment of $1 \mathrm{q}$ (for example, fig $5 \mathrm{c}$ ). Configurations of this type were recorded in $50.7 \%$ of all cells and are classified in table 2 under category A. Thickening and the presence of excrescences characterised the unpaired lateral elements. In fig 5d, an example is shown of asynapsis extending not only over the inverted segment, but also to the telomeres of one arm. This produced two extensive and free lying lateral elements. A total of $11 / 67$ cells $(16 \cdot 4 \%)$ belonged in this, category $\mathrm{B}$ (table 2 ). It is probable that a prophase configuration of this type could progress to the kind of MI cell shown in fig $3 b$, chiasma formation being restricted to one distally paired segment, probably being the longer distal $1 \mathrm{p}$. This, however, was the only MI cell out of 65

TABLE 2 Prophase analysis by microspreading. Classification of cells $(n=67)$ by $X Y$ pairing stage and inversion configuration.

\begin{tabular}{|c|c|c|c|c|c|c|c|c|c|}
\hline \multirow[t]{2}{*}{$X Y$ type* } & \multirow[t]{2}{*}{ Prophase stage } & \multicolumn{2}{|l|}{$A$} & $B$ & $C$ & $D$ & $E$ & $F$ & \multirow[t]{2}{*}{$\begin{array}{l}\text { Total } \\
\text { cells }\end{array}$} \\
\hline & & $\begin{array}{l}\text { See } \\
\text { fig } \\
5 a\end{array}$ & $\begin{array}{l}\text { See } \\
\text { fig } \\
5 b \\
\text { or c }\end{array}$ & $\begin{array}{l}\text { See } \\
\text { fig } \\
5 d\end{array}$ & $\begin{array}{l}\text { See } \\
\text { fig } \\
6 a\end{array}$ & $\begin{array}{l}\text { See } \\
\text { fig } \\
6 b\end{array}$ & $\begin{array}{l}\text { See } \\
\text { fig } \\
6 c\end{array}$ & $\begin{array}{l}22 \\
\text { normal } \\
\text { looking } \\
\text { SCs }\end{array}$ & \\
\hline 0 & Late zygotene & 2 & 8 & 4 & 4 & 1 & 1 & 2 & 22 \\
\hline I & Early pachytene & 5 & 5 & 2 & 1 & 0 & 1 & 2 & 16 \\
\hline II & Early pachytene & 1 & 3 & 0 & 0 & 0 & 0 & 1 & 5 \\
\hline III & Mid-pachytene & 0 & 0 & 0 & 0 & 0 & 0 & 1 & 1 \\
\hline IV & Late pachytene & 0 & 0 & 0 & 0 & 0 & 0 & 2 & 2 \\
\hline V & $\begin{array}{l}\text { Late pachytene } \\
\text {-diplotene }\end{array}$ & 0 & 0 & 0 & 0 & 0 & 0 & 0 & 0 \\
\hline $\begin{array}{l}\mathrm{X}+\mathrm{Y}_{\dagger}^{\dagger} \\
\%\end{array}$ & & $4_{50 \cdot 7}^{4}$ & $\begin{array}{l}6 \\
16.4\end{array}$ & $\begin{array}{l}5 \\
11.9\end{array}$ & $\begin{array}{l}3 \\
1 \cdot 5\end{array}$ & $\begin{array}{l}0 \\
3 \cdot 0\end{array}$ & $\begin{array}{l}0 \\
16.4\end{array}$ & 3 & 21 \\
\hline
\end{tabular}

${ }^{*}$ Classification of Solari. ${ }^{16}$

$\dagger \mathrm{X}$ and $\mathrm{Y}$ present as separated axes. 

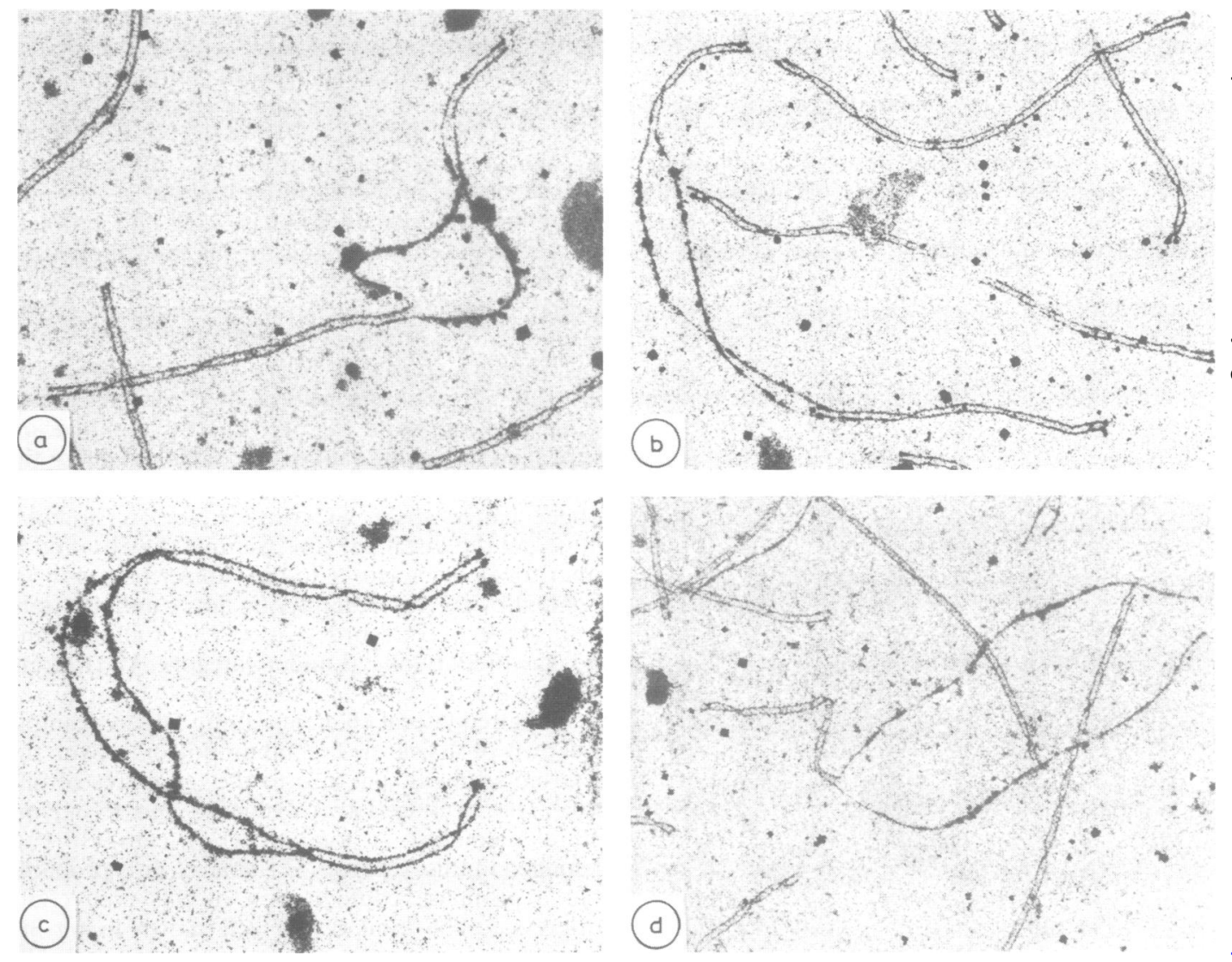

FIG 5 EM prophase spreads showing the asynapsis observed in association with the inversion.

analysed to be seen in the air dried preparations, suggesting selective elimination of the majority of such cells between pachytene and MI.

Fig $6 a, b$, and $c$ shows representative cells in categories $\mathrm{C}, \mathrm{D}$, and $\mathrm{E}$, respectively. In category $\mathrm{C}$ cells $(11.9 \%)$, synapsis had occurred at the approximate midpoint of the inversion, the flanking axes remaining, however, asynapsed (fig 6a). A single cell in category $\mathrm{D}$ showed total asynapsis over the distal segments (fig 6b). The cell in fig 6c (category E) was one of only two cells in which loop formation had been achieved, but even in these cells the loop was incompletely formed and segments of asynapsis remained. No evidence of association between the inversion bivalent and XY bivalent was found in any cell.

Finally, it was noted that $16.4 \%$ of all prophase cells analysed showed normal looking SCs with no hint of the inversion bivalent (fig 7) (category F) Such cells must be presumed to have undergone non-homologous pairing along the inverted segmen? of chromosome 1 . According to $\mathrm{XY}$ type, they were distributed across zygotene and all pachytene stages and were not exclusively seen at the late pachytener stage to which heterologous 'adjusted' synapsis is thought to be confined. ${ }^{17}$

\section{Discussion}

Our pericentric inversion chromosome 1 would appear to be behaving at prophase of meiosis in similar way to those described by Gabriel-Robez $e \bar{b}$ $a l^{5}$ and Batanian and Hultén. ${ }^{7}$ Extensive disturb $\overrightarrow{\mathbb{D}}$ ance of synapsis across the inverted region is seere in most cells, with complete loop formation being achieved in only a minority. The inversion in ouk 


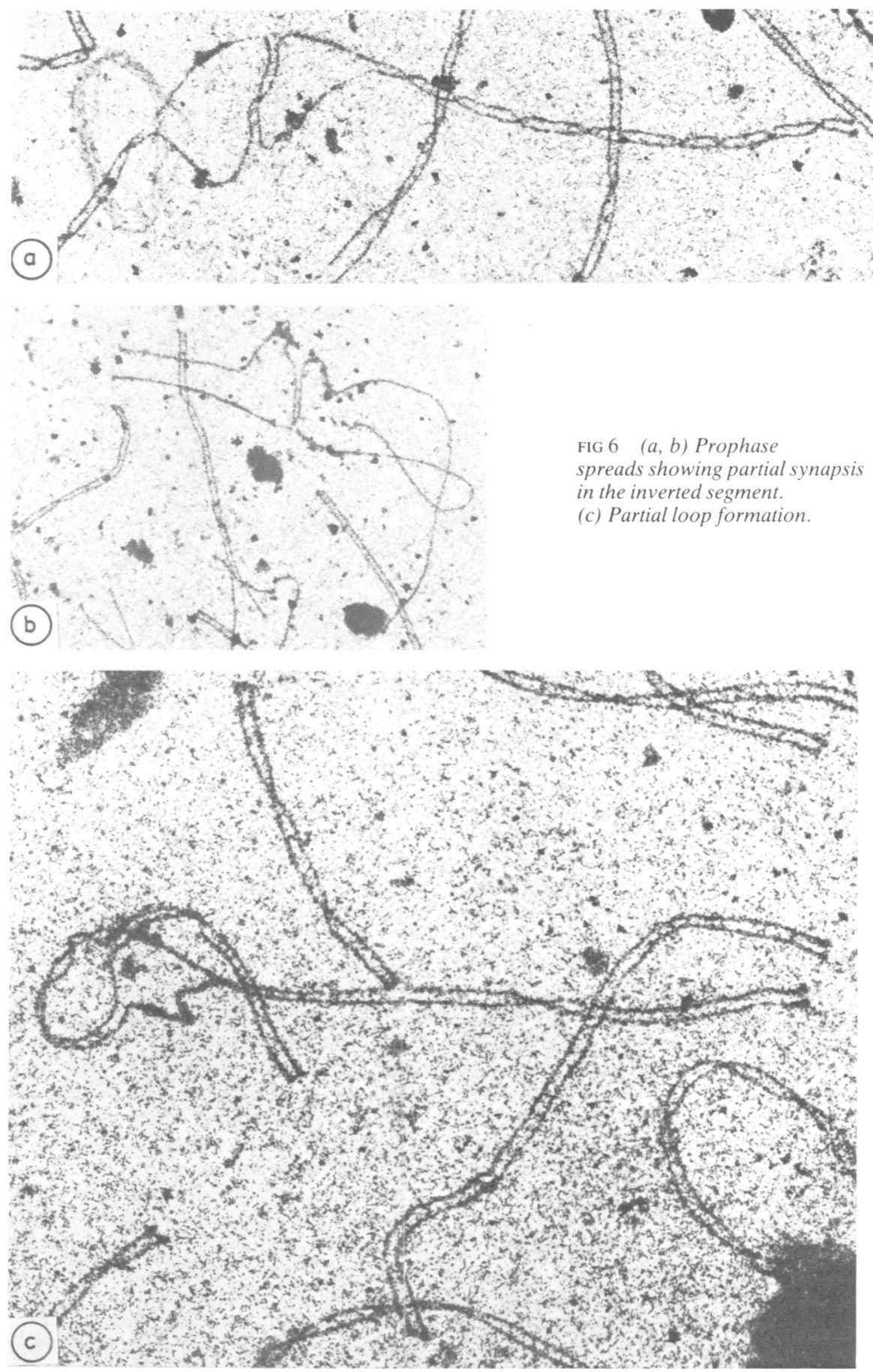




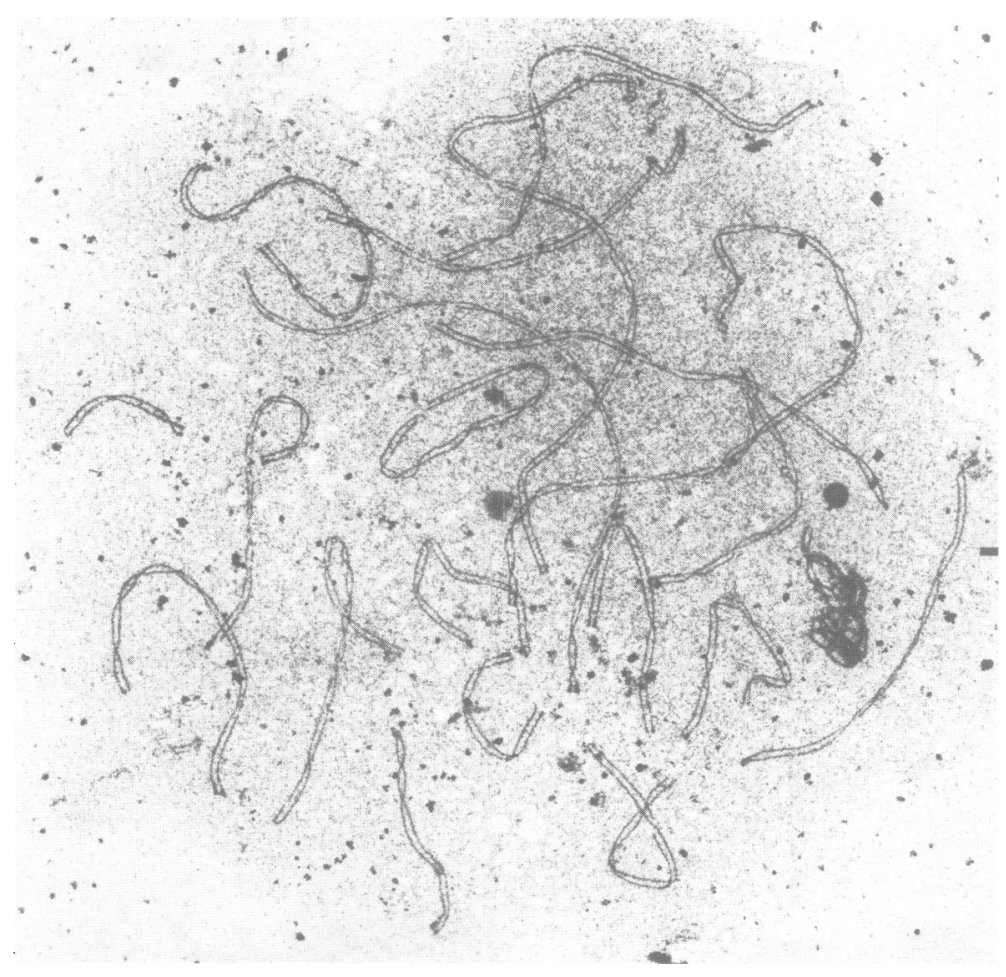

FIG 7 EM spread at late pachytene in which all synaptonemal complexes appear normal.

patient remains asynapsed along most of its length in a high proportion of prophase cells, with extensive asynapsis even surrounding those segments which have managed to achieve partial loop formation. Chiasma frequency at MI is reduced for the inversion bivalent as a whole, crossing over and chiasma formation being rare within the inverted segment itself. The combined prophase observations of asynapsis and heterologous synapsis across the inversion seen in cells as early as the zygotene stage would account for this lack of crossing over.

Since testicular biopsies for meiotic chromosome analysis are usually obtained from infertility patients, studies in human pericentric inversion cases are limited. Nevertheless, where a pachytene analysis has previously been made, albeit mostly on air dried preparations which give only limited resolution, the occurrence of loops has been reported to be 'frequent' in a case of inversion $4,{ }^{18}$ but 'rare' or 'absent' for individual cases of inversion $7,{ }^{19}$ inversion $3,{ }^{20}$ and inversion $13 .{ }^{21}$ Moreover, the rarity of full loop formation in pericentric inversions of animals, although based only on a limited number of species, has been noted for the sand rat (Psam- momys obesus), ${ }^{22}$ deer mouse (Peromysc沯 maniculatus $^{23}$ and Peromyscus sitkensis $\left.{ }^{24}\right)$, and domestic fowl (Gallus domesticus) ${ }^{25}$ Studies made in the deer mouse ${ }^{2324}$ and fowl ${ }^{25}$ show the vast majority of cells forming normal looking SCs over the whole genome, the inversions having paired heterologously over their entire lengths. The generol assumption made on classical grounds, that loops are invariably present at meiotic prophase in inve? sion heterozygotes, would thus seem to be chif lenged by these observations. The clinical implica tions of loop formation versus lack of loops af? extremely important in man, for only when loops are formed can crossing over within an inversict take place. Extensive asynapsis or early heter $\boldsymbol{Q}^{2}$ synapsis in an inversion bivalent would obvious minimise the opportunities for exchange and tie production of recombinant offspring. The proble of genetic counselling of inversion carriers and estimation of risks have been considered by number of authors in the past ${ }^{18} 192627$ and sonझ general predictions have been made concerning the probability for exchange within the loop formed an inverted segment, for example, depending 通 
absolute size of the inversion, ${ }^{27}$ or its occurrence in a male or female carrier. ${ }^{182627}$ Rarely, however, has consideration been given to the possibility that loops may not be formed or may not be complete at meiotic prophase, when crossing over is expected to occur. To date, no meiotic studies have been made on oocytes of human female inversion heterozygotes, but the general dearth of evidence for loop formation in males should clearly be taken into account when risk figures are being estimated. Recombinant offspring may well be rarer than expected. Further investigations at meiosis in carriers are required before a complete assessment of the situation with regard to pairing across inverted regions can be made.

The question of how and why a pericentric inversion in chromosome 1 in man should lead to sterility of the male carrier has been discussed elsewhere. ${ }^{7}$ The disturbance in spermatogenesis has been suggested principally to arise out of the asynapsis observed, not only within the inversion bivalent itself, but also in other members of the complement, these perhaps arising as a secondary consequence of the primary anomaly. The pairing problem in the No 1 bivalent could arise initially out of the large heterochromatic blocks on proximal 1q, such blocks tending to delay or inhibit synapsis in meiotic cells. ${ }^{1628}$ Thus, the male sterilising effects of chromosome 1 inversions in the human male could be accommodated on models which link germ cell maturation impairment to failure of synapsis. ${ }^{29} 30$ The survival of some germ cells in our patient may be related to the ability of a proportion of cells to establish heterologous pairing across the length of the inversion. We have noted that cells with an extensive region of asynapsis along most of the No 1 axis at meiotic prophase (category B cells) are rarely to be found at the MI stage, and this could indicate elimination of such cell types from the germ line. Similarly, cells with unpaired $\mathrm{X}$ and $\mathrm{Y}$ axes, with unpaired autosomes, or with other degrees of pairing failure within the inverted segment of chromosome 1 might be selectively eliminated..$^{30}$ Heterologous pairing along the inversion bivalent could, however, allow for survival, and such germ cells might therefore proceed through meiosis and spermiogenesis, pairing requirements having been satisfied. There seems no evidence, however, in our own case or in the inv(1) cases of Gabriel-Robez et $a l^{5}$ and Batanian and Hultén ${ }^{7}$ to link germ cell death with association between the inversion bivalent and the XY pair, ${ }^{31}{ }^{32}$ as no such contacts were seen in any of these cases.

It has previously been suggested that pairing initiates within the inv(1) bivalent at the midpoint of the inverted segment, ${ }^{45}$ but our own observations do not entirely support this. Possible synaptic initiation points seemed, in our material, to occur at somewhat random positions along the inversion, and were by no means always found at the midpoint. Moreover, we do not agree with Giuchaoua et $a l^{4}$ or Gabriel-Robez et $a l^{5}$ that heterologous pairing along the inversion occurs only at the late prophase stages when synaptic adjustment is occurring. ${ }^{17}$ Cells showing 23 normal looking SCs were recorded in our case at all stages of prophase from zygotene (type 0 of Solari ${ }^{16}$ ) to late pachytene (type IV) and did not increase in frequency at late prophase. It is our belief, therefore, that non-homologous synapsis across the inverted segment of bivalent No 1 can be established from the earliest stage of prophase when pairing first begins. We have argued in a previous publication for the establishment of heterologous pairing at zygotene citing a number of examples from a variety of species, ${ }^{33}$ and it has recently been shown in the deer mouse (Peromyscus sitkensis) ${ }^{24}$ that inverted segments proceed directly to heterosynapsis without an intervening homosynaptic phase. Moreover, Saadallah and Hultén ${ }^{21}$ noted the occurrence of heterosynapsed inv(13) bivalents "in the earliest pachytene substage", in a substantial proportion of cells studied at prophase. They argued for the conversion of other bivalents showing asynapsis and excrescences at early prophase into fully paired bivalents at late prophase. We do not favour their interpretation of events. Our belief is that cells showing asynapsis and the development of excrescences along unpaired lateral elements will be eliminated from the germ line. This could offer an alternative explanation for the decline in frequency of such cells noted by them towards the end of prophase.

A final point of interest arises out of the fact that some male sterile No 1 inversions in man have been inherited from a carrier mother ${ }^{3} 6$ who is herself fertile. Oogenic development might nevertheless be impaired in such women. Data from the mouse show that in the female carriers of a variety of male sterilising chromosome anomalies, oocyte numbers, ovarian size, and reproductive lifespan may all be reduced. ${ }^{30} 3435$ There could therefore be a noticeable shortening of reproductive life and an early menopause for the heterozygous mothers recorded in these cases of inversion 1 in man, and possibly for human female carriers of male sterilising anomalies in general. Few reports are available in human cytogenetics publications, but a pericentric inversion in the $\mathrm{X}$ chromosome has been reported in two sisters, both showing premature menopause. ${ }^{36} \mathrm{~A}$ second report of inversion $\mathrm{X}$ describes irregular menses in a female heterozygote of 36 years. ${ }^{37}$ Such cases would support the idea of oogenic impairment 
and depletion in oocyte numbers in such subjects. Premature menopause may perhaps be found among the causes of ascertainment in other female inversion heterozygotes.

\section{References}

1 Giraldo A, Silva E. Martinez I, Campos C, Guzman J. Pericentric inversion of chromosome 1 in three sterile brothers. Hum Genet 1981:58:226-7.

2 Toth A, Gaal M. Sara G. Laszlo J. Pericentric inversion of chromosome 1 in an azoospermic man. $J$ Med Genet 1982;19:303-5.

${ }^{3}$ Rivera H, Alvarez-Arratia MC, Moller M. Diaz M. Cantú JM. Familial inv(1)(p35.00q21.3) associated with azoospermia. Hum Genet 1984;66:165-7.

+ Guichaoua MR, Delafontaine D, Taurelle R, Taillemite JL. Morazzani MR, Luciani JM. Loop formation and synaptic adjustment in a human male heterozygous for two pericentric inversions. Chromosoma 1985;93:313-20.

5 Gabriel-Robez O, Ratomponirina C. Rumpler Y, Le Marec B. Luciani M, Guichaoua MR. Synapsis and synaptic adjustment in an infertilc human malc heterozygous for a pericentric inversion in chromosome 1. Hum Genet 1986;72:148-52.

${ }^{6}$ Barros A, Tavares MC, Gomes MP, Tavares MP. Familial inv(1) $(\mathrm{p} 36 \cdot 3 \mathrm{q} 12)$ associated with sterility. $J$ Med Genet 1986;23:90-1.

7 Batanian J, Hultén MA. Electron microscopic investigations of synaptonemal complexes in an infertile human male carrier of a pericentric inversion inv(1)(p32q42) regular loop formation but defective synapsis including a possible inter-chromosomal cffect. Hum Genet (in press).

* Sumner AT, Evans HJ, Buckland RA. A new technique for distinguishing between human chromosomes. Nature 1971:232:31-2.

${ }^{9}$ Sumner AT. A simple technique for demonstrating centromeric heterochromatin. Exp Cell Res 1972;75:304-6.

11 Evans EP. Breckon G, Ford CE. An air-drying method for meiotic preparations from mammalian testes. Cytogenetics 1964:3:289-94.

1 Carr DH, Walker J. Carbol fuchsin as a stain for mammalian chromosomes. Stain Technol 1961;36:233-6.

12 Chandley AC, Fletcher J. Centromere staining at meiosis in man. Humangenetik 1973;18:247-52.

13 Chandley AC, Goctz P, Hargreave TB, Joseph AM, Speed RM. On the nature and extent of $X Y$ pairing at meiotic prophase in man. Cytogenet Cell Genet 1984:38:241-7.

14 Hultén M. Chiasma distribution at diakinesis in the normal human malc. Hereditas 1974:76:55-78.

15 Chandley AC, Edmond P. Maclean N, Fletcher J, Watson GS Cytogenetics and infertility in man: results of a five-year survey of men attending a subfertility clinic. Part II. Testicular histology and mciosis. Ann Hum Genet 1976;40:165-76.

${ }^{16}$ Solari AJ. Synaptonemal complexes and associated structures in microspread human spermatocytes. Chromosoma 1980;81:31537.

17 Moses MJ, Poorman PA, Roderick TH, Davisson MT. Synaptonemal complex analysis of mousc chromosomal rearrangements. IV. Synapsis and synaptic adjustment in two paracentric inversions. Chromosoma 1982:84:457-74.

1x van der Linden AGJM. Pearson PL, van de Kemp JJP Cytological assessment of meiotic exchange in a human male with a pericentric inversion of chromosome No 4. Cytogenet Cell Genet 1975:14:120-39.

1" Winsor EJT, Palmer CG. Ellis PM, Hunter JLP, Ferguson-
Smith MA. Meiotic analysis of a pericentric inversion? $\operatorname{inv}(7)(\mathrm{p} 22 \mathrm{q} 32)$, in the father of a child with a duplication deletion of chromosome 7. Cytogenet Cell Genet 1978:20:16984.

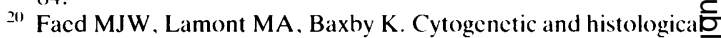
studies of testicular biopsies from subfertile men with chromoñ some anomaly. J Med Genet 1982;19:49-56.

2) Saadallah N. Hultén M. EM investigations of surface spreaç synaptonemal complexes in a human male carrier of pericentric inversion inv(13)( 12 q 14): the role of heterosynapsis for spermatocyte survival. Ann Hum Genet 1986;50:369-83.

22 Ashley T, Moses MJ. Solari AJ. Fine structure and behaviour of a pericentric inversion in the sand rat Psammomys obesus. $J$ Celtw Sci $1981 ; 50: 105-19$

23 Greenbaum IF, Reed MJ. Evidence for heterosynaptic pairing्ञ of the inverted segment in pericentric inversion heterozygotes ob the deer mouse (Peromyscus maniculatus). Cytogenet Cell Genein 1984:38:106-11.

${ }^{2+}$ Halc DW. Hetcrosynapsis and suppression of chiasmata withing heterozygous pericentric inversions of the Sitka deer mouse Chromosoma 1986:94:425-32.

${ }^{25}$ Kaclbling M. Fechheimer NS. Synaptonemal complex analysio of a pericentric inversion in chromosome 2 of domestic fowl Gallus domesticus. Cytogenet Cell Genet 1985;39:82-6.

26 Sutherland GR. Gardiner AJ, Carter RF. Familial pericentrie inversion of chromosome 19. inv(19)(p13q13) with a note ord genetic counselling of pericentric inversion carriers. Clin Genet 1976:10:54-9.

27 Kaiser P. Pericentric inversions. Problems and significance for clinical genetics. Hum Genet 1984;68:1-47.

2x Scuánez. HN, Armada JL. Barroso C. Rezende C, de Silva VFO The meiotic chromosomes of Cebus apella (Cebidac. Platyrrhi ni). Cytogenet Cell Genet 1983:36:517-24.

29) Miklos GLG. Sex chromosome pairing and male fertilityo Cytogenet Cell Genet 1974:13:558-77.

311 Burgoyne PS. Baker T. Meiotic pairing and gametogenic failure In: Evans CW. Dickinson HG, eds. Controlling events is meiosis. Cambridge: Co of Biologists, 1984:349.

${ }^{31}$ Forejt J. X-Y involvement in male sterility caused by autosome translocations: a hypothesis. In: Crosignani PG. Rubin BL, eds Genetic control of gamete production and function. New York? Academic Press/Grunc and Stratton. 1982:135-51.

32 Rosenmann A. Wahrman J. Richler C. Voss R. Persitz A Goldman B. Meiotic association between the XY chromosomes and unpaired autosomal elements as a cause of human mals sterility. Cytogenet Cell Genet 1985:39:19-29.

3 Speed RM. Oocyte development in XO foctuses of man an mouse: the possible role of heterologous $X$-chromosome pairing in germ cell survival. Chromosoma 1986;94:115-24.

${ }^{34}$ Burgoyne PS. Mahadevaiah S. Mittwoch U. A reciprocis autosomal translocation which causes male sterility in the mous also impairs oogenesis. J Reprod Fertil 1985:75:647-52.

35 Mittwoch U. Mahadevaiah S, Setterfield LA. ChromosomaFanomalies that cause male sterility in the mouse also reducer ovary size. Genet Res Camb 1984:44:219-24.

3. Soler A. Salami C. Balmes I, et al. Pericentric X chromosome in

37 a family. Clin Genet 1981:20:234-9. pericentric inversion of $\mathrm{X}$ chromosome. Hum GeneX 1978:45:115-22.

Correspondence and requests for reprints to $\mathrm{Dr} A$ Chandley, MRC Clinical and Population Cytogene $=0$ tics Unit, Western General Hospital, Crewe Roadळ Edinburgh EH4 2XU. 